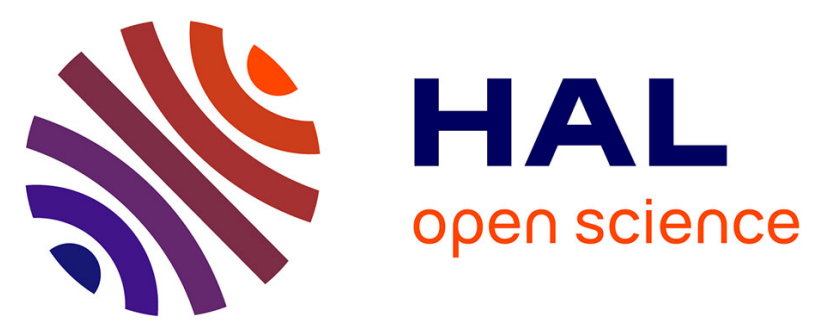

\title{
Comparative study of different cocoa (Theobroma cacao L.) clones in terms of their phytoprostanes and phytofurans contents
}

Daniel León-Perez, Sonia Medina, Julián Londoño-Londoño, Marina

Cano-Lamadrid, Ángel Carbonell-Barrachina, Thierry Durand, Alexandre

Guy, Camille Oger, Jean-Marie Galano, Federico Ferreres, et al.

\section{To cite this version:}

Daniel León-Perez, Sonia Medina, Julián Londoño-Londoño, Marina Cano-Lamadrid, Ángel Carbonell-Barrachina, et al.. Comparative study of different cocoa (Theobroma cacao L.) clones in terms of their phytoprostanes and phytofurans contents. Food Chemistry, 2019, 280, pp.231-239. 10.1016/j.foodchem.2018.12.072 . hal-02417429

\section{HAL Id: hal-02417429 \\ https://hal.science/hal-02417429}

Submitted on 18 Dec 2019

HAL is a multi-disciplinary open access archive for the deposit and dissemination of scientific research documents, whether they are published or not. The documents may come from teaching and research institutions in France or abroad, or from public or private research centers.
L'archive ouverte pluridisciplinaire HAL, est destinée au dépôt et à la diffusion de documents scientifiques de niveau recherche, publiés ou non, émanant des établissements d'enseignement et de recherche français ou étrangers, des laboratoires publics ou privés. 


\title{
Comparative study of different cocoa (Theobroma cacao L.) clones in terms of their phytoprostanes and phytofurans contents
}

\author{
Daniel León-Perez ${ }^{\mathrm{a}, \mathrm{b}}$, Sonia Medina ${ }^{\mathrm{a}, \mathrm{c}, *}$, Julián Londoño-Londoño ${ }^{\mathrm{b}}$, Marina Cano-Lamadrid ${ }^{\mathrm{d}}$, \\ Ángel Carbonell-Barrachina ${ }^{\mathrm{d}}$, Thierry Durand ${ }^{\mathrm{e}}$, Alexandre Guy ${ }^{\mathrm{e}}$, Camille Oger ${ }^{\mathrm{e}}$, \\ Jean-Marie Galano ${ }^{\mathrm{e}}$, Federico Ferreres ${ }^{\mathrm{a}}$, Claudio Jiménez-Cartagena ${ }^{\mathrm{b}}$, José Restrepo-Osorno ${ }^{\mathrm{f}}$, \\ Ángel Gil-Izquierdo ${ }^{\mathrm{a}, *}$ \\ ${ }^{a}$ Research Group on Quality, Safety and Bioactivity of Plant Foods, Department of Food Science and Technology, CEBAS (CSIC), P.O. Box 164, 30100 Campus University \\ Espinardo, Murcia, Spain \\ b Instituto de Ciencia y Tecnología Alimentaria - INTAL, Itagüi, Antioquia, Colombia \\ ${ }^{\mathrm{c}}$ Faculty of Engineering, Food Engineering Program, Corporación Universitaria Lasallista, Caldas, Antioquia, Colombia \\ ${ }^{\mathrm{d}}$ Department of Agro-Food Technology, Miguel Hernández University of Elche, Carretera Beniel km 3.2, 03312 Orihuela, Alicante, Spain \\ e Institut des Biomolécules Max Mousseron (IBMM), UMR 5247, CNRS, Université de Montpellier, ENSCM, Montpellier, France \\ ${ }^{\mathrm{f}}$ National Federation of Cocoa, FEDECACAO, Colombia
}

Keywords:

Mass spectrometry

Phytofurans

Phytoprostanes

Oxidative stress

Cocoa beans

PUFAs

\begin{abstract}
A B S T R A C T
Cocoa has been widely discussed as a bioactive food rich in sensory stimulation and health benefits. However, no information has been provided concerning phytoprostanes (PhytoPs) and phytofurans (PhytoFs) in cocoa. These compounds are of interest because they play a role in the regulation of immune function. The present study included 31 cocoa clones. The PhytoPs and PhytoFs were quantified by UHPLC-QqQ-MS/MS. The total PhytoPs and PhytoFs contents ranged from 221.46 to $1589.83 \mathrm{ng} \mathrm{g}^{-1}$ and from 1.18 to $13.13 \mathrm{ng} \mathrm{g}^{-1}$, respectively. The profiles of the PhytoPs and PhytoFs identified in the cocoa beans showed significant differences among the clones analysed. The results indicate that dry fermented cocoa beans are rich in PhytoPs and PhytoFs, which may represent an additional benefit of the consumption of foods derived from cocoa.
\end{abstract}

\section{Introduction}

The interest in the consumption of foods that provide health benefits and possess attractive sensorial characteristics has always stimulated research, much of which has focused on bioactive compounds that promote health or provide sensory stimulation (Marseglia, Sforza et al., 2014). Accordingly, cocoa and its derivatives have been well studied with this approach. Cocoa has been recognized as an important source of polyphenols (Demidchik, 2015), flavonoids (Patras, Milev, Vrancken, \& Kuhnert, 2014), catechins, procyanidins (Cádiz-Gurrea et al., 2014), amino acids (Marseglia, Palla, \& Caligiani, 2014), polypeptides, and oligopeptides (Marseglia, Sforza et al., 2014). To this list may include compounds that add sensory properties to the product, known as "single-origin" (Torres-Moreno, Tarrega, Costell, \& Blanch, 2012), which are of interest to both researchers and consumers. Transversally, these studies may repeatedly denote homogeneity, but the increased understanding of food chemistry that they have provided has underpinned new guidelines and motivated consumption. In addition, nowadays, the focus on food characteristics related to geographic origin is often prioritized. Furthermore, the study of compounds or metabolites not reported so far ("unknown") is facilitated by the use of analytical tools with higher resolution and sensitivity.

According to these perspectives, the study of novel compounds like phytoprostanes (PhytoPs) and phytofurans (PhytoFs) is of interest

\footnotetext{
Abbreviations: BHA, Butylated hydroxyanisole; ALA, $\alpha$-linolenic acid; FAMEs, fatty acids methyl esters; GC-MS, Gas chromatography-mass spectrometry; IsoPs,

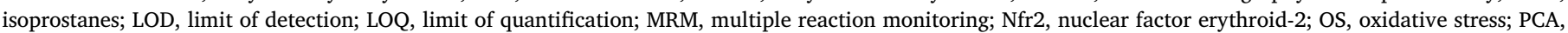

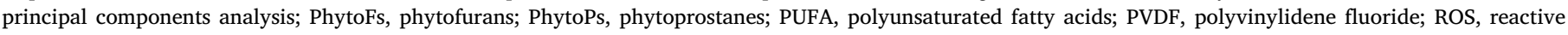

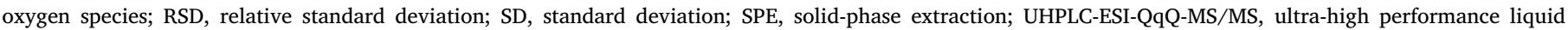
chromatography-electrospray ionization-triple quadrupole mass spectrometry

* Corresponding authors at: Quality, Safety and Bioactivity of Plant Foods Group, Department of Food Science and Technology, CEBAS-CSIC, P.O. Box 164, 30100 Espinardo, Murcia, Spain (S. Medina).

E-mail addresses: smescudero@cebas.csic.es (S. Medina), angelgil@cebas.csic.es (Á. Gil-Izquierdo).
} 


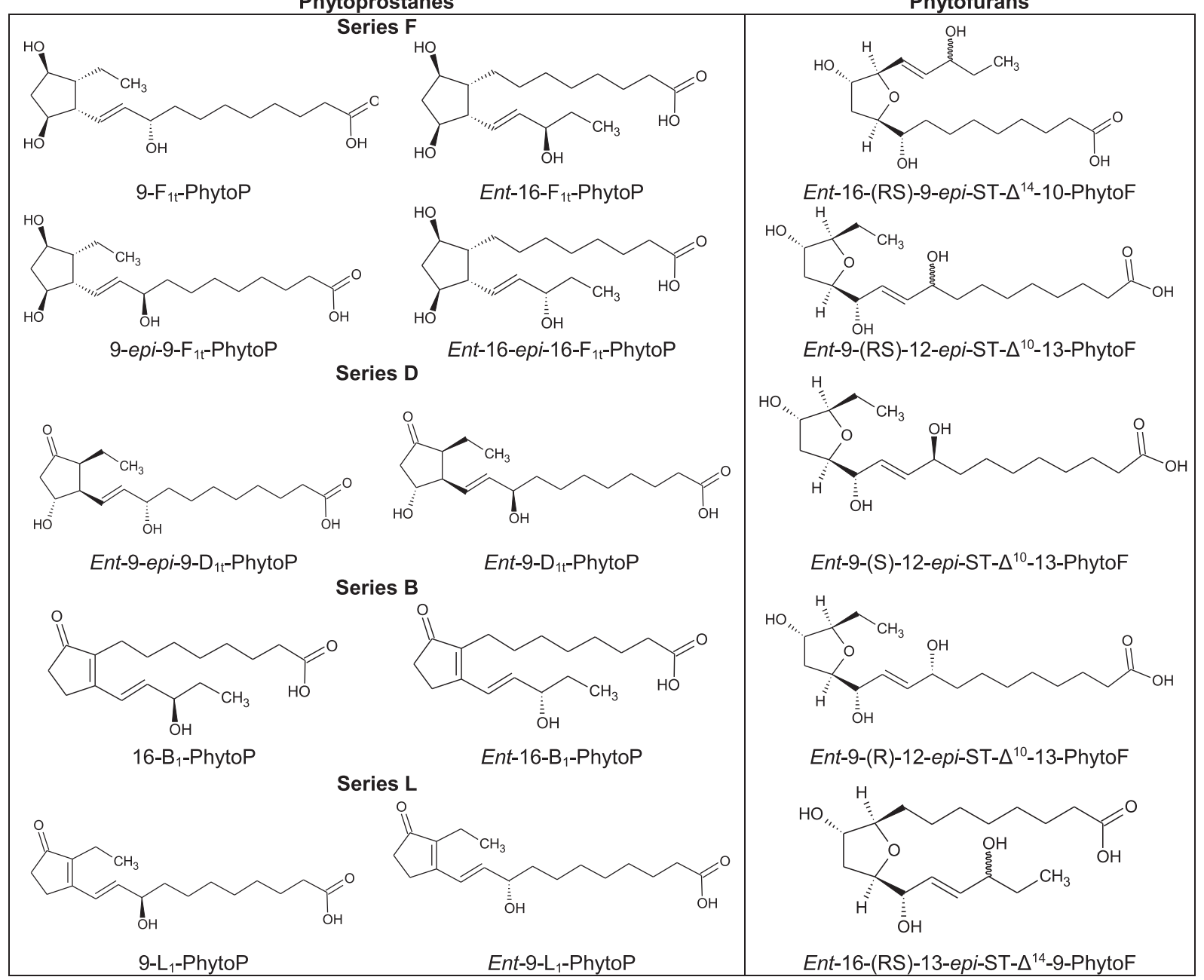

Fig. 1. Chemical structures of phytoprostanes and phytofurans (named according to the ((Collado-González et al., 2016) Taber/Roberts nomenclature).

because it is known that they play a role in the regulation of immune function (Barden et al., 2009) and display anti-inflammatory and apoptosis-inducing activities, among others, similar to other prostanoids (Durand et al., 2011).

These metabolites are prostaglandin-like compounds (plant oxylipins) derived from the lipid peroxidation of polyunsaturated fatty acids (PUFAs), such as $\alpha$-linolenic acid (ALA, C18:3n-3), via a nonenzymatic free-radical-catalyzed pathway (Jahn, Galano, \& Durand, 2010). In the biosynthesis of IsoPs which are oxidative stress (OS) markers in mammals, a carbon radical undergoes a 5-exo-trig cyclization (Baldwin rules (Baldwin, 1976; Baldwin, Thomas, Kruse, \& Silberman, 1977)) to form the cyclopentane ring of isofurans (IsoFs) (Jahn, Galano, \& Durand, 2008; Morrow et al., 1990). Meanwhile, the PhytoPs - like PhytoFs - are oxylipins which may be formed from ALA, but they require a high oxygen tension (higher than $21 \%$ ) to attack the same carbon radical as PhytoPs and form compounds containing a tetrahydrofuran ring. So, the IsoFs are characterized by a tetrahydrofuran ring and two side chains. These bioactive compounds act as endogenous mediators capable of protecting cells from damage under various conditions related to OS (Loeffler et al., 2005).

In the scientific literature, PhytoPs and PhytoFs have been reported in numerous natural or unprocessed products, as also in processed products (as shown Supplementary Table S1), but, so far, these compounds have not been reported in cocoa beans. For this reason, the objective of the present work was to assess, for the first time, the concentrations of PhytoPs and PhytoFs in cocoa bean from different clones. Hence, a comparative study of the content of PhytoPs and
PhytoFs by UHPLC-MS/MS was developed in cocoa beans obtained from the same farm, the same period of flowering and ripeness of the fruits. In addition, the same process of fermentation and drying was assured. Only the variety of the genetic material of the cocoas was varied. The profile of these metabolites was studied in conjunction with the fatty acids levels. The value of these matrices as a source of these largely unknown oxylipins needs to be addressed in order to plan nutritional trials devoted to shed some light on their biological activity.

\section{Materials and methods}

\subsection{Chemicals and reagents}

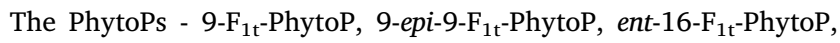

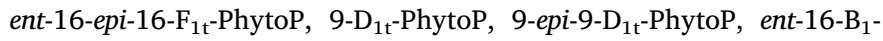
PhytoP, 16- $\mathrm{B}_{1}-$ PhytoP, ent-9- $\mathrm{L}_{1}-\mathrm{PhytoP}$, and $9-\mathrm{L}_{1}-\mathrm{PhytoP}$ - were synthesized according to our published procedures (El Fangour et al., 2004; El Fangour, Guy, Vidal, Rossi, \& Durand, 2005; Pinot et al., 2008). The PhytoFs - ent-16-(RS)-9-epi-ST- $\Delta^{14}-10-P h y t o F$, ent-9-(RS)-12-epi-ST- $\Delta^{10}$ 13-PhytoF, ent-9-(S)-12-epi-ST- $\Delta^{10}$-13-PhytoF, ent-9-(R)-12-epi-ST- $\Delta^{10}$. 13-PhytoF, and ent-16-(RS)-13-epi-ST- $\Delta^{14}$-9-PhytoF - were synthesized according to our previous reports (Cuyamendous et al., 2015) (Fig. 1). Hexane, sodium hydroxide $(\mathrm{NaOH})$, anhydrous sodium sulfate, and water for LC-MS were obtained from Panreac (Castellar Del Vallés, Barcelona, Spain). Fatty acid methyl ester (FAME) Mix Supelco GLC-50, GLC-100, CLA isomers (c9 t11 CLA and t10 c12 CLA), nonanoic acid (C9:0), heptadecanoic acid (C17:0), boron trifluoride $\left(\mathrm{BF}_{3}\right)$, and 
Table 1

Cacao clones evaluated and their respective characteristics. Small bean size: ( $<1.4 \mathrm{~g} /$ grain); middle (1.4-1.6 g/ grain); big ( $\geq 1.6 \mathrm{~g} /$ grain).

\begin{tabular}{|c|c|c|}
\hline Samples & Variety & Grain size \\
\hline Criollo moderno - 1 & Criollo moderno & Big \\
\hline Criollo moderno - 2 & Criollo moderno & Big \\
\hline Criollo moderno - 3 & Criollo moderno & Middle \\
\hline Criollo - 1 & Criollo & Big \\
\hline Criollo - 2 & Criollo & Big \\
\hline Criollo - 3 & Criollo & Big \\
\hline Regional - 1 & Regional & Middle \\
\hline Regional - 2 & Regional & Small \\
\hline Regional - 3 & Regional & Middle \\
\hline Regional - 4 & Regional & Big \\
\hline Regional - 5 & Regional & Big \\
\hline Regional - 6 & Regional & Middle \\
\hline Regional - 7 & Regional & Small \\
\hline Regional - 8 & Regional & Middle \\
\hline Regional - 9 & Trinitario & Big \\
\hline Regional - 10 & Regional & Middle \\
\hline Regional - 11 & Regional & Big \\
\hline Albino - 1 & Forastero & Middle \\
\hline Albino - 2 & Forastero & Middle \\
\hline CCN-51 & Forastero & Middle \\
\hline FMT-1 & Forastero & Middle \\
\hline FTU-6 & Forastero & Middle \\
\hline CAU-37 & Forastero & Small \\
\hline EET-8 & Trinitario & Big \\
\hline EET-96 & Trinitario & Middle \\
\hline FMAC-11 & Trinitario & Middle \\
\hline FMAC-12 & Trinitario & Middle \\
\hline ICS-1 & Trinitario & $\mathrm{Big}$ \\
\hline ICS-39 & Trinitario & Big \\
\hline ICS-95 & Trinitario & Small \\
\hline TSH-565 & Trinitario & Small \\
\hline
\end{tabular}

Bis-Tris (bis(2-hydroxyethyl) amino-tris(hydroxymethyl)methane) were obtained from Sigma-Aldrich Chemie GmbH (Steinheim, Germany). Methylene chloride was purchased from Labscan Ltd (Dublin, Ireland). All LC-MS grade solvents, methanol, and acetonitrile were purchased from J.T. Baker (Phillipsburg, New Jersey, USA). The SPE cartridges (Strata X-AW $33 \mu, 100 \mathrm{mg} / 3 \mathrm{~mL}$ ) were acquired from Phenomenex (Torrance, CA, USA), and the Sep-Pak ${ }^{\circledR}$ classic C18 cartridges from Waters (Milford, MA).

\subsection{Geographical origin of the samples}

Cocoa (Theobroma cacao) trees were cultivated, and their cobs fermented and extracted, at the "Cannes" (Maceo) experimental farm, located $132 \mathrm{~km}$ from Medellín, Department of Antioquia, Colombia (Supplementary Material). Cannes is situated $1000 \mathrm{~m}$ above sea level $\left(6^{\circ} 31^{\prime} 16.62^{\prime \prime} \mathrm{N}\right.$ and $\left.-74^{\circ} 49^{\prime} 25.57^{\prime \prime} \mathrm{W}\right)$, the annual average temperature is $23^{\circ} \mathrm{C}$, the annual precipitation is $2700 \mathrm{~mm}$, and the mean relative humidity is $80 \%$. The study included 31 different clones of cocoa beans grown on the experimental farm, which were classified according to their denomination on the farm (three criollos, three criollos modernos, four forasteros, two forasteros albinos, ten regionals, and nine trinitarios) (Table 1). For the harvest of samples, the period of cocoa grown known as "traviesa" (crossbred) was selected (from May to June of 2016); this was after the first flowering of the year, but before the main harvest. The fruit ripeness was determined by an expert farmer; healthy and representative cobs were selected from each clone batch grown on the experimental farm. The extraction of the cocoa beans was done the same day for all the samples. The beans were separated inside plastic meshes and labelled for subsequent identification. The meshes with the beans were arranged in fermentation drawers. The fermentation process was developed in a place covered in the same area of cocoa crop and was performed at room temperature spontaneously and in wooden drawers designed in three columns by three rows with a capacity of
$150 \mathrm{~kg}$ per drawer. The three central horizontal drawers were used, and labelled as drawer 1 , drawer 2 and drawer 3. The monitoring and evolution was developed under the guidance of a farmer and a FEDECACAO (National Federation of Cocoa-Colombia) technician with expertise in the cocoa fermentation process. The fermentation was performed with beans that were healthy and free of impurities such as leaves or insects, for six days, guaranteeing the death of the embryo in each bean.

A natural drying process was performed on wooden platforms in a marquee dryer. The meshes were opened and the beans were carefully extended, ensuring that the clones were not mixed. The drying was completed on the seventh day, as indicated by the cracking of the beans and the, development of a kidney shape and brown colour. Samples (18 cocoa beans in triplicate) were processed and analysed up to one month after collection on the farm. The samples were stored at $-80^{\circ} \mathrm{C}$ before being extracted for further analyses.

\subsection{Processing of cocoa beans}

The PhytoPs and PhytoFs from the cocoa beans samples were isolated using a dispersive liquid-liquid extraction followed by an SPE, according to a procedure described by Collado-González, Medina et al. (2015) with modifications. Each sample was ground in a coffee mill to obtain a semi-fine cocoa powder $(<1000 \mu \mathrm{m})$, homogenized, and weighed (about $2 \mathrm{~g}$ ), before being added to a mortar together with $10 \mathrm{~mL}$ of BHA dissolved in methanol $\left(1 \mathrm{~g} \mathrm{~L}^{-1}\right)$. Then, the homogenized sample was transferred to a centrifuge tube and centrifuged for $10 \mathrm{~min}$ at $4{ }^{\circ} \mathrm{C}$ and $2000 \mathrm{~g}$. The supernatant was filtered in a C18 Sep-Pak (previously activated with $10 \mathrm{~mL}$ of methanol and $10 \mathrm{~mL}$ of water). Exactly $1 \mathrm{~mL}$ of the extract was diluted with $10 \mathrm{~mL}$ of hexane, $2 \mathrm{~mL}$ of methanol, and $2 \mathrm{~mL}$ of BIS-TRIS buffer ( $0.02 \mathrm{M}, \mathrm{HCl}, \mathrm{pH}=7$ ); between each addition the mixture was stirred vigorously. The emulsion obtained was subjected to SPE using a Strata X-AW cartridge $(100 \mathrm{mg}$ / $3 \mathrm{~mL}$ ); prior to this, the cartridge was conditioned and equilibrated with $2 \mathrm{~mL}$ of hexane, $2 \mathrm{~mL}$ of methanol, and $2 \mathrm{~mL}$ of milliQ water. After removal of the non-subject compounds, the cartridge was washed with $2 \mathrm{~mL}$ of hexane, $2 \mathrm{~mL}$ of milliQ water, $2 \mathrm{~mL}$ of a solution of methanol/ milliQ water $(1 / 3, v / v)$, and $2 \mathrm{~mL}$ of acetonitrile. The target compounds were eluted with $1 \mathrm{~mL}$ of methanol and dried using a SpeedVac concentrator (Savant SPD121P, Thermo Scientific, MA, USA). The dry extracts were reconstituted with $200 \mu \mathrm{L}$ of mobile phase (solvent A, a mixture of milliQ water/0.01\% $(v / v)$ acetic acid, and solvent B, a solution of methanol/0.01\% $(v / v)$ acetic acid, in a proportion of 90:10 v/ $\nu$, respectively). The samples were filtered through $0.45-\mu \mathrm{m}$ PVDF filters (Millipore, MA, USA) and $20 \mu \mathrm{L}$ of each sample were analysed. The samples were analysed in triplicate.

Stock solutions of PhytoFs and PhytoPs were prepared in methanol/ water $(50: 50, v / v)$, to facilitate the ionization process in the mass spectrometer, at a concentration of $1000 \mathrm{nM}$ for each compound and stored in Eppendorf tubes at $-80{ }^{\circ} \mathrm{C}$. Twelve successive dilutions were prepared for the calibration curve (with $\mathrm{R}^{2}$ value higher than 0.99 ).

\subsection{Measurements}

\subsubsection{Phytofurans and phytoprostanes analyses}

The identification and quantification of PhytoFs and PhytoPs were performed using a UHPLC coupled to a 6460 triple quadrupole-MS/MS (Agilent Technologies, Waldbronn, Germany), with a $\mathrm{BEH} \mathrm{C}_{18}$ analytical column $(2.1 \times 50 \mathrm{~mm}, 1.7 \mu \mathrm{m})$ (Waters, Milford, MA). The column temperature was $6^{\circ} \mathrm{C}$. The mobile phases consisted of water/acetic acid (99.99:0.01, $v / v$ ) (A) and methanol/acetic acid (99.99:0.01, $v / v$ ) (B) and $20 \mu \mathrm{L}$ of the diluted extract was injected at a flow of $0.2 \mathrm{~mL} \mathrm{~min}^{-1}$. The following gradient program was used: $60 \% \mathrm{~B}$ at $0 \mathrm{~min}, 62 \% \mathrm{~B}$ at $2 \mathrm{~min}$, $62.5 \% \mathrm{~B}$ at $4 \mathrm{~min}, 65 \% \mathrm{~B}$ at $8 \mathrm{~min}$, and $60 \% \mathrm{~B}$ at $8.01 \mathrm{~min}$. The acquisition time was $8.01 \mathrm{~min}$ for each sample, with a post-run of $1.5 \mathrm{~min}$ for column equilibration. Analysis was performed in the negative mode by 
Table 2

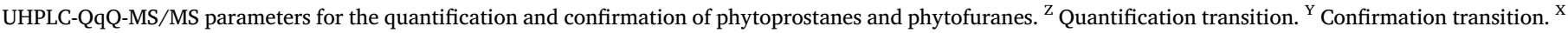
Coeluting diastereoisomers quantified together.

\begin{tabular}{|c|c|c|c|c|c|}
\hline Compound & Retention time (min) & ESI mode & MRM transition $(m / z)$ & Fragmentor (V) & Collision energy (V) \\
\hline \multicolumn{6}{|l|}{ Phytoprostanes } \\
\hline \multirow{2}{*}{ Ent-16-epi-16- $\mathrm{F}_{1 \mathrm{t}}-\mathrm{Phyto}^{\mathrm{X}}$} & 1.583 & Negative & $327.1>283.2^{Z}$ & 80 & 15 \\
\hline & & & $327.1>225.1^{Y}$ & 80 & 15 \\
\hline \multirow[t]{2}{*}{ 9-F Ft $^{- \text {PhytoP }}$} & 1.631 & Negative & $327.2>273.1$ & 110 & 15 \\
\hline & & & $327.2>171.0$ & 110 & 15 \\
\hline \multirow[t]{2}{*}{ Ent-16- $\mathrm{F}_{1 \mathrm{t}}-\mathrm{Phyto}^{\mathrm{X}}$} & 1.712 & Negative & $327.2>283.2$ & 80 & 10 \\
\hline & & & $327.2>225.1$ & 80 & 10 \\
\hline \multirow[t]{2}{*}{ 9-epi-9-F ${ }_{1 \mathrm{t}}-\mathrm{PhytoP}$} & 1.785 & Negative & $327.2>272.8$ & 110 & 10 \\
\hline & & & $327.2>171.0$ & 110 & 10 \\
\hline \multirow[t]{2}{*}{ 9- $\mathrm{D}_{1 \mathrm{t}}$-PhytoP } & 1.791 & Negative & $325.2>307.3$ & 100 & 4 \\
\hline & & & $325.2>134.7$ & 100 & 4 \\
\hline \multirow[t]{2}{*}{ 9-epi-9-D ${ }_{1 \mathrm{t}}$-PhytoP } & 2.022 & Negative & $325.2>307.2$ & 100 & 7 \\
\hline & & & $325.2>134.9$ & 100 & 7 \\
\hline \multirow{2}{*}{ 16-B B $_{1}$-PhytoP } & 2.620 & Negative & $307.2>223.2$ & 100 & 10 \\
\hline & & & $307.2>235.1$ & 100 & 100 \\
\hline \multirow[t]{2}{*}{ 9-- $\mathrm{L}_{1}$-PhytoP } & 3.079 & Negative & $307.2>185.1$ & 110 & 7 \\
\hline & & & $307.2>196.7$ & 110 & 7 \\
\hline \multicolumn{6}{|l|}{ Phytofurans } \\
\hline \multirow[t]{2}{*}{ Ent-9-(RS)-12-epi-ST- $\Delta^{10}-13-P h y t o F$} & 0.906 & Negative & $344.0>300.0$ & 110 & 10 \\
\hline & & & $344.0>255.9$ & 110 & 10 \\
\hline \multirow[t]{2}{*}{ Ent-16-(RS)-9-epi-ST- $\Delta^{14}$-10-PhytoF } & 1.501 & Negative & $343.9>209.0$ & 90 & 12 \\
\hline & & & $343.9>201.1$ & 90 & 12 \\
\hline \multirow[t]{2}{*}{ Ent-16-(RS)-13-epi-ST- $\Delta^{14}$-9-PhytoF } & 1.523 & Negative & $343.0>171.1$ & 90 & 22 \\
\hline & & & $343.0>97.2$ & 90 & 22 \\
\hline
\end{tabular}

multiple reaction monitoring (MRM). The MS parameters fragmentor (ion optics: capillary exit voltage), collision energy, and preferential MRM transition of the corresponding analytes were optimized for each analyte (Table 2). The source parameters used were gas flow: $8 \mathrm{~L} \mathrm{~min}^{-1}$; gas temperature: $325^{\circ} \mathrm{C}$; sheath gas temperature: $350^{\circ} \mathrm{C}$; jetstream gas flow: $12 \mathrm{~L} \mathrm{~min}^{-1}$; nebulizer: $30 \mathrm{psi}$; capillary voltage: $3000 \mathrm{~V}$; and nozzle voltage: $1750 \mathrm{~V}$. Data acquisition and processing were performed using MassHunter software version B.04.00 (Agilent Technologies). The elution gradient and mass spectrometric parameters were as described previously (Collado-González, Medina, et al., 2015). The quantification of PhytoPs and PhytoFs detected in cocoa clones was performed using authentic standard according to standard curve freshly prepared as mentioned in the previous Section 2.3.

\subsubsection{Fatty acid profile}

The analysis of fatty acids was performed by methylating these compounds in situ, following the procedure described by Taber, Morrow, and Jackson Roberts (1997) and later improved by Trigueros and Sendra (2015). The cocoa beans were ground, homogenized, and weighed. A sample of approximately $40 \mathrm{mg}$ was transferred into a test tube. $60 \mu \mathrm{L}$ of $\mathrm{C} 17: 0$ in $\mathrm{n}$-hexane solution as internal standard $\left(-20 \mathrm{mg} \mathrm{mL}^{-1}\right.$ solution in HPLC grade $\mathrm{n}$-hexane) was added. Then, $100 \mathrm{~mL}$ of methylene chloride and $1 \mathrm{~mL}$ of $0.5 \mathrm{M} \mathrm{NaOH}$ in methanol were added, and the tubes were heated in a water bath at $90^{\circ} \mathrm{C}$ for 10 min. One milliliter of $\mathrm{BF}_{3}$ in methanol was added and the mixture was left at room temperature $\left(25^{\circ} \mathrm{C}\right)$ for $30 \mathrm{~min}$. One milliliter of distilled water and $600 \mathrm{~mL}$ of hexane were added, and then the fatty acids methyl esters (FAMEs) were extracted by vigorous shaking for about $1 \mathrm{~min}$. Following centrifugation, aliquots were dried with anhydrous sodium sulfate and the top layer was transferred into a vial flushed with nitrogen, which was stored at $-20{ }^{\circ} \mathrm{C}$ until analysis. The FAMEs were analysed using GC-MS with a SupraWax-280 column, 100\% polyethylene glycol (Teknokroma S. Co. Ltd., 165 Barcelona, Spain; $30 \mathrm{~m} \times 0.25 \mathrm{~mm} \times 0.25 \mu \mathrm{m}$ film thickness). The analyses were carried out using helium as carrier gas at a flow rate of $1.1 \mathrm{~mL} \mathrm{~min}^{-1}$ and a program as follows: initial temperature $80^{\circ} \mathrm{C}$, hold for $2 \mathrm{~min}$; rate of increase of $8.0^{\circ} \mathrm{C} \mathrm{min}{ }^{-1}$ to $160^{\circ} \mathrm{C}$; rate of $4^{\circ} \mathrm{C} \mathrm{min}{ }^{-1}$ from 160 to $220^{\circ} \mathrm{C}$, hold for $13 \mathrm{~min}$; and rate of $10^{\circ} \mathrm{C} \mathrm{min}^{-1}$ from 220 to $260^{\circ} \mathrm{C}$, hold for $6 \mathrm{~min}$. The injector and detector temperatures were held at 230 and $260^{\circ} \mathrm{C}$, respectively; $0.5 \mu \mathrm{L}$ of the extract was injected. The analyses were run in duplicate.

\subsubsection{Statistical analysis}

To determine the effect of each factor on each individual PhytoP, PhytoF, and PUFA, an analysis of variance (ANOVA, $\mathrm{p} \leq 0.05$ ), Pearson's correlation analysis of the different variables studied and multiple range test (Tukey's test) were carried out using the SPSS program, version 23.0 (SPSS Inc., Chicago, IL, USA). Mean values were compared by the LSD (Least Significant Difference) test when significant interactions between factors were found.

\section{Results and discussion}

Oxidative stress is a complex chemical and physiological phenomenon that accompanies practically all the biotic and abiotic stresses in plants (Hasanuzzaman, Hossain, da Silva, \& Fujita, 2012). It develops as a result of the overproduction and accumulation of reactive oxygen species (ROS) (Demidchik, 2015).

In this study, we selected the Cannes experimental farm because it is located in an area of cocoa production in the region of Antioquia, Colombia. This farm has a rich clone plantation; the cocoa trees are the same age and there are many different clones. In addition, the abiotic stresses (such as drought, salinity, cold, high light/UV-B, heat, air pollution, heavy metals, mechanical wounding, and nutritional deficiency (Nakabayashi \& Saito, 2015)) influencing the beans were considered homogeneous for all samples, as was the biotic stress experienced during fermentation. These variables, although influencing the formation of the target metabolites, were assumed to be constant and, although they may have exerted some influence on the results obtained, the impact of the genetic resource (clones) was assumed to be far superior. However, as far as we know, this is the first report where different classes of PhytoPs have been detected and quantified in fermented and dried cocoa beans of different clones; and as a result it was determined statistically different PhytoP and PhytoF levels were found among the different cocoa beans clones (Tables 3 and 4). They were independent of a classification like criollo (and criollo moderno), regional, forastero, or trinitario cocoa. The results of statistical tests are shown in Supplementary Table S2. 
Table 3

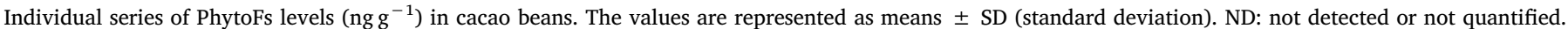

\begin{tabular}{|c|c|c|c|}
\hline Samples & $\begin{array}{l}\text { ent-16-(RS)-9-epi-ST- } \\
\Delta^{14}-10-\mathrm{PhytoF}\end{array}$ & ent-9-(RS)-12-epi-ST- $\Delta^{10}-13-P h y t o F+e n t-9-(\mathrm{S})-12$-epi-ST- $\Delta^{10}{ }^{13}-\mathrm{PhytoF}+$ ent-9-(R)-12-epi-ST- $\Delta^{10}-13-\mathrm{PhytoF}$ & $\begin{array}{l}\text { ent-16-(RS)-13-epi- } \\
\text { ST- } \Delta^{14}-9-P h y t o F\end{array}$ \\
\hline Criollo moderno - 1 & $1.13 \pm 0.08$ & $0.99 \pm 0.05$ & $1.51 \pm 0.15$ \\
\hline Criollo moderno - 2 & $\mathrm{ND}$ & ND & $1.26 \pm 0.34$ \\
\hline Criollo moderno - 3 & $1.09 \pm 0.06$ & ND & $1.55 \pm 0.62$ \\
\hline Criollo - 1 & ND & ND & ND \\
\hline Criollo - 2 & $1.18 \pm 0.07$ & $0.97 \pm 0.22$ & $3.31 \pm 0.12$ \\
\hline Criollo - 3 & $\mathrm{ND}$ & ND & $\mathrm{ND}$ \\
\hline Regional - 1 & ND & $\mathrm{ND}$ & $\mathrm{ND}$ \\
\hline Regional - 2 & $1.48 \pm 0.13$ & $1.12 \pm 0.10$ & $2.96 \pm 0.36$ \\
\hline Regional - 3 & $0.99 \pm 0.05$ & ND & $2.19 \pm 0.07$ \\
\hline Regional - 4 & $1.49 \pm 0.07$ & $1.55 \pm 0.04$ & $1.11 \pm 0.05$ \\
\hline Regional - 5 & $0.95 \pm 0.08$ & $\mathrm{ND}$ & $1.00 \pm 0.09$ \\
\hline Regional - 6 & $1.88 \pm 0.18$ & $2.21 \pm 0.18$ & ND \\
\hline Regional - 7 & ND & ND & ND \\
\hline Regional - 8 & $2.70 \pm 0.39$ & $2.94 \pm 0.21$ & $7.49 \pm 0.30$ \\
\hline Regional - 9 & $1.08 \pm 0.15$ & ND & $1.74 \pm 0.30$ \\
\hline Regional - 10 & $1.33 \pm 0.28$ & $1.37 \pm 0.10$ & $2.38 \pm 0.37$ \\
\hline Regional - 11 & $1.09 \pm 0.00$ & ND & $2.24 \pm 0.24$ \\
\hline Albino - 1 & $1.20 \pm 0.03$ & ND & $2.13 \pm 0.35$ \\
\hline Albino - 2 & $1.56 \pm 0.21$ & $1.20 \pm 0.08$ & $2.79 \pm 0.35$ \\
\hline CCN-51 & $1.80 \pm 0.11$ & ND & $3.29 \pm 0.07$ \\
\hline FMT-1 & $1.39 \pm 0.03$ & $1.10 \pm 0.13$ & $3.06 \pm 0.26$ \\
\hline FTU-6 & $1.00 \pm 0.17$ & ND & $1.01 \pm 0.13$ \\
\hline CAU-37 & $1.38 \pm 0.13$ & $1.58 \pm 0.31$ & $2.06 \pm 0.06$ \\
\hline EET-8 & ND & ND & $1.38 \pm 0.17$ \\
\hline EET-96 & $1.05 \pm 0.03$ & ND & $2.14 \pm 0.80$ \\
\hline FMAC-11 & $1.38 \pm 0.20$ & $1.08 \pm 0.11$ & $1.82 \pm 0.18$ \\
\hline FMAC-12 & $1.01 \pm 0.02$ & $1.14 \pm 0.06$ & $1.60 \pm 0.47$ \\
\hline ICS-1 & ND & ND & $\mathrm{ND}$ \\
\hline ICS-39 & ND & ND & ND \\
\hline ICS-95 & $1.18 \pm 0.19$ & $\mathrm{ND}$ & $\mathrm{ND}$ \\
\hline TSH-565 & $1.58 \pm 0.09$ & $1.30 \pm 0.12$ & $2.23 \pm 0.32$ \\
\hline
\end{tabular}

PhytoPs and PhytoFs were detected in all the cocoa beans samples analysed, except for some specific samples in which they were below the LOD (Tables 3 and 4) and with respect to recovery percentages were in the range of 85 and 123\% for all the analytes (PhytoPs and PhytoFs) according to our recent published validated method (Domínguez-Perles et al., 2018). The identification of these free PhytoPs was confirmed according to their pseudomolecular ions, the characteristic MS/MS fragmentation product ions (quantification and confirmation transitions), and their corresponding retention times (Collado-González, Medina, et al., 2015). PhytoPs and PhytoFs are formed non-enzymatically as regio- and stereoisomeric mixtures, so the analytical conditions employed in our study did not allow enantiomeric separation; therefore, they are quantified in the cocoa beans samples as racemic mixtures of PhytoPs and PhytoFs (Fig. 1). It is important to note that ent-16-epi-16- $\mathrm{F}_{1 \mathrm{t}}$-PhytoP + ent-16- $\mathrm{F}_{1 \mathrm{t}}$-PhytoP are epimers at position C16; ent-9-(RS)-12-epi-ST- $\Delta^{10}-13-P h y t o F+$ ent-9-(S)-12-epi-ST- $\Delta^{10}$ 13-PhytoF + ent-9-(R)-12-epi-ST- $\Delta^{10}$-13-PhytoF are a racemic mixture at position $\mathrm{C} 9(50 \% 9 \mathrm{R}$ and $50 \% 9 \mathrm{~S})$; and $16-\mathrm{B}_{1 \mathrm{t}}$-PhytoP + ent- $16-\mathrm{B}_{1 \mathrm{t}^{-}}$ PhytoP and 9- $\mathrm{L}_{1}-\mathrm{PhytoP}+$ ent-9- $\mathrm{L}_{1}-\mathrm{PhytoP}$ represent racemic mixtures that are not separable in our chromatographic conditions (ColladoGonzález, Medina, et al., 2015).

The total PhytoPs and PhytoFs amounts in the cocoa beans ranged from 221.46 to 1589.83 and 1.18 to $13.13 \mathrm{ng} \mathrm{g}^{-1}$, respectively, being Criollo-2 and Regional-8 the clones with the highest concentration of PhytoPs and PhytoFs, respectively (Tables 3 and 4). Moreover, the greatest proportion of the PhytoPs profile of the samples was represented by the series $\mathrm{F}_{1 \mathrm{t}^{-}}$, while the series $\mathrm{B}_{1^{-}}, \mathrm{L}_{1^{-}}$, and $\mathrm{D}_{1 \mathrm{t}^{-}}$were detected at lower levels, corresponding to ranges of 209.46 to 1558.44 , 3.04 to $46.35,2.11$ to 26.34 , and 1.82 to $21.79 \mathrm{ng} \mathrm{g}^{-1}$, respectively. These results are consistent with those reported previously for Passiflora edulis Sims shell, macroalgae, and red wine (Barbosa et al., 2015; Marhuenda et al., 2015; Medina et al., 2017). In relation to PhytoFs, there are few studies of these compounds. Cuyamendous et al. (2015) described for the first time the synthesis of PhytoFs and quantified the compound ent-16(RS)-13-epi-ST- $\Delta^{14}$-9-PhytoF in nuts (pine nuts and walnuts) and seeds (flaxseeds and chia seeds). Yonny et al. (2016) studied PhytoFs in melon leaves, but they did not find ent-16(RS)-13epi-ST- $\Delta^{14}$-9-PhytoF; conversely, in cocoa beans, this PhytoF was the most abundant (Table 3). Accordingly, the profile of the individual series differed significantly among the samples of the cocoa clones analysed. Furthermore, differences in genotype could also affect the apparent PhytoPs content and series in plant samples (Carrasco-Del Amor et al., 2016; Collado-González, Medina et al., 2015; ColladoGonzález, Moriana et al., 2015). On this matter, a study of different types of nuts (walnut, macadamia, and pecan) was reported by Carrasco-Del Amor et al. (2017). This work showed that the PhytoP profile varied according to the nut type, and possibly according to the given genotype within specie. This could explain the results in our study - where the qualitative and quantitative PhytoP profiles varied greatly among the cocoa clones, but they were also affected by factors such as the growing conditions and chemical composition with respect to ALA, OA, LA and other lipids, and tocopherols. These compounds varied tremendously within the species, according to environmental variability, geographical origin, temperature, and irrigation (Zhu, Taylor, Sommer, Wilkinson, \& Wirthensohn, 2015). Further studies are needed to investigate if the cultivation of the same cocoa clones in different areas has a real effect on the production of specific PhytoPs and PhytoFs.

The importance of PhytoPs and PhytoFs is related not only to plant physiology but also to their biological effects in humans, since they are part of our diet and their presence has already been reported in human biofluids (Barden et al., 2009). They can reach the gastrointestinal tract and interact with the gut microflora. In fact, there is evidence that these bioactive lipid derivatives can modify the functions of the immune systems (Durand et al., 2011) and neuronal systems (Minghetti et al., 2014). Furthermore, there is similarity between the plant and mammalian stress responses. In this sense, Medina et al. (2017) tentatively proposed that the effect of PhytoPs on human physiological 


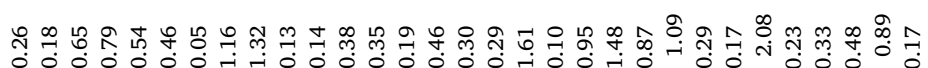
$1+1+1+1+1+1+1+1+1+1+1+1+1+1+1+1+1+1+1+1+1+1+1+1+1+1+1+1+1+1+1$
$+1+1$

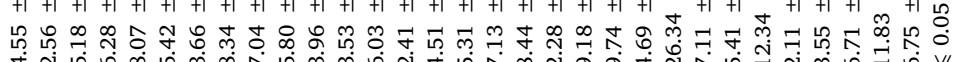

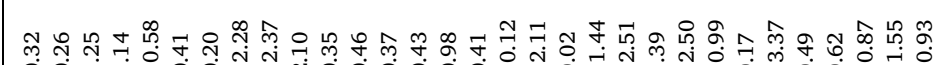
O.

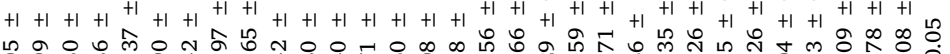

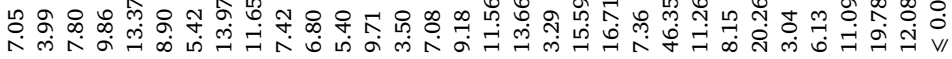

สิ

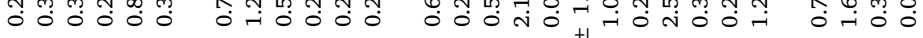
$\begin{array}{lll}1+1+1+1+1+1 & +1+1+1+1+1+1 & +1+1+1+1+1+1+1+1+1+1+1+1 \\ 0 & +1+1+1+1\end{array}$

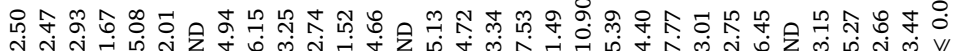

$\ddot{z}$

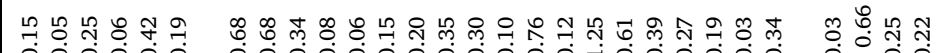

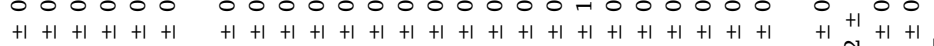

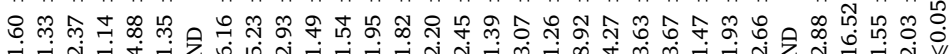
-

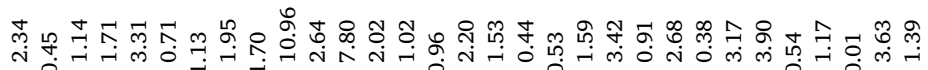
$+1+1+1+1+1+1+1+1+1+1+1+1+10+1+1+1+1+1+1+1+1+1+1+10+1+1+1+1$

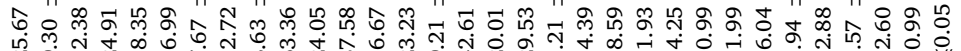

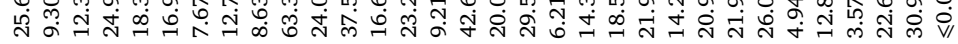

œ ن

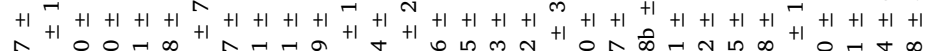

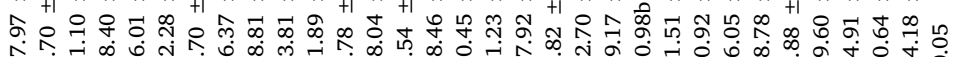

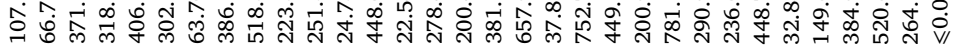

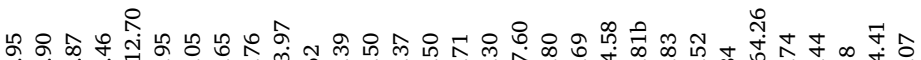
तì $+1+1+1+1+1+1+1+1+1+1+1+1+1+1+1+1+1+1+1+1+1+1+1+1+1+1+1+1+1+1+1$

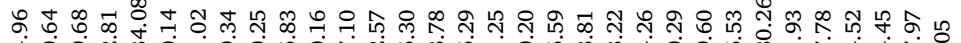

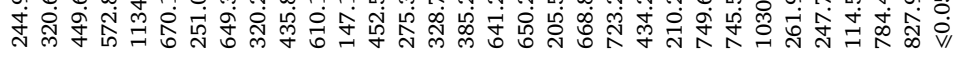

구

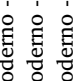

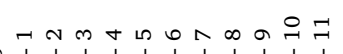


mechanisms could be related to different metabolic processes. For instance, PhytoPs can activate the stress-sensing mammalian transcription factor Nrf2 (nuclear factor erythroid-2) (Heiss et al., 2014). This transcription factor is an emerging regulator of cellular resistance to oxidants and it controls and induces expression of the antioxidant response. Accordingly, Nrf2 activation contributes to several beneficial bioactivities of natural products. In this sense, the benefits of fruit consumption may be due to the interactions of different bioactive compounds (flavonoids, o ther $\mathrm{p}$ olyphenols, a nd P hytoPs, among others), since they could activate the Nrf2 pathway and increase expression of the antioxidant response (Waltenberger, Mocan, Šmejkal, Heiss, \& Atanasov, 2016).

In relation to cocoa or its derivatives, the capacity of this food has been hypothesized to activate the Nrf2 factor, but it is associated with flavan-3-ol(-) - epicatechin (Shah et al., 2010). Accordingly, the results of the present study show the presence and diverse concentrations of the different series of PhytoPs in cocoa beans, and can formulate the contribution of PhytoPs in favor of the reduction of the risk of ischemic heart disease. As previously stated by Carrasco-Del Amor et al. (2015) and Marhuenda et al. (2015), this study also supports the importance of PhytoPs and PhytoFs as relevant OS biomarkers in plants.

Furthermore, the FAME profile was determined with the objective of comparing it with the concentrations and profiles of PhytoPs and PhytoFs; as mentioned above, ALA is the precursor of both PhytoPs and PhytoFs, so some relationship between this fatty acid and the oxylipins under study here was expected. Other fatty acids from cocoa beans were measured in order to find $\mathrm{p}$ ossible $\mathrm{c}$ orrelations $\mathrm{w}$ ith $\mathrm{P}$ hytoPs and PhytoFs synthesis. The result of this analysis was expressed as $\mathrm{g} \mathrm{Kg}^{-1}$ and it is presented in Table 5 . The most important fatty acids, for types of cocoa beans, were C16:0, and C18:0 and C18:1. Pearson correlations were made between the totals and each of the series of PhytoPs, PhytoFs, and FAMEs. The results showed medium linear correlations, with a level of significance of $\mathrm{p}<0.05$ between the total PhytoPs and C18:1
( $\mathrm{r}=0.357)$; total PhytoFs and C16:1 and C20:0 ( $\mathrm{r}=0.406$ and $\mathrm{r}=-0.477$, respectively); 9- $\mathrm{F}_{1 \mathrm{t}}-\mathrm{PhytoP}$ and C18:1 $(\mathrm{r}=0.433)$; 9-epi-9$\mathrm{D}_{1 \mathrm{t}}$-PhytoP and C14:0 $(\mathrm{r}=-0.439)$; ent-16- $\mathrm{B}_{1}-$ PhytoP $+16-\mathrm{B}_{1}$-PhytoP and $\mathrm{C} 16: 1 \quad(\mathrm{r}=-0.395)$; ent-9- $\mathrm{L}_{1}-\mathrm{PhytoP}+9-\mathrm{L}_{1}-\mathrm{PhytoP}$ and $\mathrm{C} 16: 1$ $(\mathrm{r}=-0.391)$; ent-9-(RS)-12-epi-ST- $\Delta^{10}$-13-PhytoF + ent-9-(S)-12-epiST- $\Delta^{10}-13-$ PhytoF + ent-9-(R)-12-epi-ST- $\Delta^{10}-13$-PhytoF and C14:0 $(\mathrm{r}=0.648)$; ent-16-(RS)-13-epi-ST- $\Delta^{14}-9-\mathrm{PhytoF}$ and C14:0, C16:0; $\mathrm{C} 18: 0$, and $\mathrm{C} 18: 3(\mathrm{r}=0.438, \mathrm{r}=0.424, \mathrm{r}=-0.416$, and $\mathrm{r}=0.485$, respectively). Although the correlation of the results is positive in this preliminary analysis, it should not be attributed solely to this correlation among the series of the PhytoPs, PhytoFs and FAMEs. In future assays, it should be considered other physicochemical phenomena linked to the biotic and abiotic factors that can occur both in the harvest and postharvest periods of the cocoa fruits. According to previous studies, the formation of these compounds develops from the attack of ROS on ALA. But, as we indicated previously in the results, only ent-16-(RS)13-epi-ST- $\Delta^{14}$-9-PhytoF showed a positive correlation, in accordance with Cuyamendous et al. (2015). Notably, flaxseeds showed the highest C18:1 level but had a relatively low ent-16-(RS)-13-epi-ST- $\Delta^{14}-9-$ PhytoF level compared to walnuts and chia seeds, that contained less C18:1. However, pine nuts had the lowest ALA level and the lowest ent-16(RS)-13-epi-ST- $\Delta^{14}$-9-PhytoF level; but, it was also established in the same study that the relative concentrations of ent-16-(RS)-13-epi-ST$\Delta^{14}$-9-PhytoF do not necessarily express the relative C18:1 concentrations in walnuts and chia seeds.

\section{Conclusions}

The study of PhytoPs and PhytoFs can be considered recent, and it has been carried out in several matrices; such as rice, walnuts, almonds, melon plants (leaves), macroalgae, wines and musts, vegetables oils, among others. However, this is the first identification and quantification of these compounds in dry fermented cocoa beans.

Table 5

FAMEs levels in cacao beans. The values are represented as $\mathrm{g} \mathrm{Kg}^{-1}$.

\begin{tabular}{|c|c|c|c|c|c|c|c|c|c|}
\hline Sample & Myristic acid & Palmitic acid & Palmitic acid & Stearic acid & Oleic acid & Isomer & Linoleic acid & $\alpha$-Linolenic acid & Gadoleic acid \\
\hline & $\mathrm{C} 14: 0$ & $\mathrm{C} 16: 0$ & C16:1 & C18:0 & C18:1 & $\mathrm{C} 18: 1$ & C18:2 & $\mathrm{C} 18: 3$ & C20:0 \\
\hline Criollo moderno - 1 & 0.13 & 48.06 & 0.51 & 51.04 & 51.07 & 0.75 & 7.98 & 0.40 & 1.80 \\
\hline Criollo moderno - 2 & 0.24 & 105.06 & 1.24 & 114.15 & 114.80 & 1.93 & 13.30 & 0.67 & 4.27 \\
\hline Criollo moderno - 3 & 0.24 & 92.34 & 1.21 & 110.41 & 121.60 & 2.11 & 11.94 & 0.86 & 3.60 \\
\hline Criollo - 1 & 0.54 & 90.18 & 0.83 & 135.60 & 127.94 & 2.04 & 12.56 & 0.88 & 4.51 \\
\hline Criollo - 2 & 0.11 & 92.45 & 0.89 & 104.09 & 113.62 & 2.07 & 9.75 & 0.73 & 3.28 \\
\hline Criollo - 3 & 0.49 & 106.09 & 0.97 & 128.48 & 130.84 & 1.56 & 13.62 & 0.92 & 4.61 \\
\hline Regional - 1 & 0.21 & 99.18 & 0.74 & 106.02 & 114.11 & 1.55 & 13.53 & 0.84 & 3.64 \\
\hline Regional - 2 & 0.13 & 77.79 & 0.93 & 83.44 & 89.37 & 1.47 & 10.92 & 0.72 & 2.44 \\
\hline Regional - 3 & 0.13 & 102.95 & 0.96 & 146.62 & 133.79 & 2.24 & 13.17 & 0.76 & 5.05 \\
\hline Regional - 4 & 0.13 & 78.45 & 1.01 & 94.56 & 94.82 & 1.45 & 10.21 & 0.58 & 3.36 \\
\hline Regional - 5 & 0.11 & 73.67 & 0.79 & 77.58 & 92.88 & 1.96 & 10.14 & 0.66 & 2.73 \\
\hline Regional - 6 & 0.18 & 86.97 & 0.72 & 111.82 & 108.42 & 1.44 & 12.22 & 0.75 & 3.49 \\
\hline Regional - 7 & 0.18 & 77.35 & 0.67 & 101.38 & 96.95 & 1.25 & 8.70 & 0.46 & 3.43 \\
\hline Regional - 8 & 0.33 & 79.24 & 1.31 & 72.74 & 84.95 & 1.20 & 9.02 & 0.71 & 2.45 \\
\hline Regional - 9 & 0.15 & 78.32 & 1.11 & 104.83 & 98.65 & 1.90 & 11.37 & 0.61 & 3.60 \\
\hline Regional - 10 & 0.17 & 66.16 & 0.74 & 79.17 & 81.47 & 1.34 & 8.20 & 0.52 & 2.57 \\
\hline Regional - 11 & 0.15 & 78.73 & 0.93 & 119.17 & 107.22 & 1.98 & 14.12 & 0.79 & 4.03 \\
\hline Albino - 1 & 0.15 & 78.73 & 0.93 & 119.17 & 107.22 & 1.98 & 14.12 & 0.79 & 4.03 \\
\hline Albino - 2 & 0.12 & 89.27 & 0.87 & 107.04 & 116.61 & 1.66 & 10.89 & 0.69 & 3.67 \\
\hline CCN-51 & 0.09 & 93.43 & 0.91 & 106.23 & 114.75 & 1.69 & 9.91 & 0.87 & 3.66 \\
\hline FMT-1 & 0.15 & 57.34 & 0.41 & 69.10 & 72.32 & 0.85 & 5.73 & 0.42 & 2.04 \\
\hline FTU-6 & 0.17 & 70.59 & 1.09 & 88.17 & 85.30 & 1.68 & 8.88 & 0.57 & 2.92 \\
\hline CAU-37 & 0.07 & 30.29 & 0.21 & 36.27 & 36.64 & 0.47 & 4.35 & 0.24 & 1.09 \\
\hline EET-8 & 0.17 & 103.32 & 0.67 & 151.59 & 138.63 & 1.58 & 12.33 & 0.72 & 4.74 \\
\hline EET-96 & 0.14 & 73.89 & 0.72 & 102.46 & 99.76 & 1.62 & 10.00 & 0.62 & 3.10 \\
\hline FMAC-11 & 0.11 & 99.56 & 1.01 & 117.90 & 124.88 & 1.94 & 14.75 & 0.84 & 3.64 \\
\hline FMAC-12 & 0.16 & 88.01 & 0.91 & 92.59 & 99.55 & 1.40 & 8.30 & 0.55 & 3.13 \\
\hline ICS-1 & 0.15 & 72.71 & 0.70 & 94.49 & 91.99 & 1.35 & 12.10 & 0.62 & 3.03 \\
\hline ICS-39 & 0.14 & 58.91 & 0.52 & 75.29 & 72.40 & 1.01 & 9.06 & 0.49 & 2.36 \\
\hline ICS-95 & 0.40 & 103.33 & 0.67 & 97.73 & 116.13 & 1.42 & 11.90 & 0.86 & 3.98 \\
\hline TSH-565 & 0.26 & 84.24 & 0.82 & 102.16 & 103.55 & 1.28 & 9.77 & 0.62 & 3.86 \\
\hline
\end{tabular}


The results obtained show dry fermented cocoa beans to be a rich source of PhytoPs and PhytoFs. In fact, the individual concentrations of the PhytoPs and PhytoFs reported in the present study are higher than in other matrices studied. Moreover, the concentrations of the PhytoPs and PhytoFs determined in the different cocoa clones showed significant differences among them, but unrelated to the classification: criollo, criollo moderno, regional, forastero, and trinitario. One well known characteristic of cocoa is the quantity and quality of its fatty acids and fats, which implies their theoretical correlation with the profiles of the studied compounds. But, taking into account the lack of correlation with ALA and other fatty acids, the variation in the concentrations of PhytoPs and PhytoFs may be attributed to the biotic and abiotic stressors to which the plants are exposed. Also, this variation may be due to other characteristics of the matrix, such as the presence of antioxidants and equivalent molecules, followed by variations in the genetic resource, the origin of the cocoa crop, and the fermentation and drying processes. This information may be very useful for cocoa industries and for the development of the cocoa growing regions.

\section{Conflict of interest}

The authors declare no conflict of interest.

\section{Acknowledgements}

We are grateful to Dr. David Walker (native English speaker) for his review of the English grammar and style of the current report. The authors are also grateful to the Special Cooperation Agreement 4600003348 celebrated between the Department of Antioquia Secretary of Agriculture and Rural Development, the University Corporation Lasallista, the National Cocoa Association of Colombia, and the University of Antioquia, whose objective is to join forces to identify, characterize, and evaluate the genetic resource of fine Colombian aroma cocoa and form the CECE (elite collection of special cocoa) for the Department of Antioquia. We also thank the farmer Mr. Evelio González, for his assistance in his experimental farm (Cannes). This work was partially funded by the "Fundación Séneca de la Región de Murcia" Grupo de Excelencia 19900/GERM/15. This work was funded by the Spanish Research Council (CEBAS-CSIC) and the CNRS, by "Projet International de Coopération Scientifique" (PICS-2015261141) and the Spanish project AGL2017-83386-R from the Spanish Ministry of Science, Innovation and Universities.

\section{Appendix A. Supplementary data}

Supplementary data to this article can be found online at https:// doi.org/10.1016/j.foodchem.2018.12.072.

\section{References}

Baldwin, J. E. (1976). Rules for ring closure. Journal of the Chemical Society Chemical Communications, 18, 734-736.

Baldwin, J. E., Thomas, R. C., Kruse, L. I., \& Silberman, L. (1977). Rules for ring closure: Ring formation by conjugate addition of oxygen nucleophiles. The Journal of Organic Chemistry, 42(24), 3846-3852.

Barbosa, M., Collado-González, J., Andrade, P. B., Ferreres, F., Valentão, P., Galano, J.-M., Gil-Izquierdo, Á. (2015). Nonenzymatic $\alpha$-Linolenic Acid Derivatives from the Sea: Macroalgae as Novel Sources of Phytoprostanes. Journal of Agricultural and Food Chemistry, 63(28), 6466-6474.

Barden, A. E., Croft, K. D., Durand, T., Guy, A., Mueller, M. J., \& Mori, T. A. (2009). Flaxseed oil supplementation increases plasma F1-phytoprostanes in healthy men. The Journal of Nutrition, 139(10), 1890-1895.

Cádiz-Gurrea, M. L., Lozano-Sanchez, J., Contreras-Gámez, M., Legeai-Mallet, L., Fernández-Arroyo, S., \& Segura-Carretero, A. (2014). Isolation, comprehensive characterization and antioxidant activities of Theobroma cacao extract. Journal of Functional Foods, 10, 485-498.

Carrasco-Del Amor, A. M., Aguayo, E., Collado-González, J., Guy, A., Galano, J.-M., Durand, T., \& Gil-Izquierdo, Á. (2016). Impact of packaging atmosphere, storage and processing conditions on the generation of phytoprostanes as quality processing compounds in almond kernels. Food Chemistry, 211, 869-875.
Carrasco-Del Amor, A. M., Aguayo, E., Collado-González, J., Guy, A., Galano, J.-M., Durand, T., \& Gil-Izquierdo, Á. (2017). Impact of processing conditions on the phytoprostanes profile of three types of nut kernels. Free Radical Research, 51(2), 141-147.

Carrasco-Del Amor, A. M., Collado-Gonzalez, J., Aguayo, E., Guy, A., Galano, J. M., Durand, T., \& Gil-Izquierdo, A. (2015). Phytoprostanes in almonds: Identification, quantification, and impact of cultivar and type of cultivation. RSC Advances, 5(63), 51233-51241.

Collado-González, J., Medina, S., Durand, T., Guy, A., Galano, J.-M., Torrecillas, A., ... GilIzquierdo, A. (2015). New UHPLC-QqQ-MS/MS method for quantitative and qualitative determination of free phytoprostanes in foodstuffs of commercial olive and sunflower oils. Food Chemistry, 178, 212-220.

Collado-González, J., Moriana, A., Girón, I. F., Corell, M., Medina, S., Durand, T., ... Gil Izquierdo, A. (2015). The phytoprostane content in green table olives is influenced by Spanish-style processing and regulated deficit irrigation. LWT - Food Science and Technology, 64(2), 997-1003.

Collado-González, J., Pérez-López, D., Memmi, H., Gijón, M. C., Medina, S., Durand, T., ... Gil-Izquierdo, A. (2016). Effect of the season on the free phytoprostane content in Cornicabra extra virgin olive oil from deficit-irrigated olive trees. Journal of the Science of Food and Agriculture, 96(5), 1585-1592.

Cuyamendous, C., Leung, K. S., Durand, T., Lee, J. C. Y., Oger, C., \& Galano, J. M. (2015) Synthesis and discovery of phytofurans: Metabolites of [small alpha]-linolenic acid peroxidation. Chemical Communications, 51(86), 15696-15699.

Demidchik, V. (2015). Mechanisms of oxidative stress in plants: From classical chemistry to cell biology. Environmental and Experimental Botany, 109, 212-228.

Domínguez-Perles, R., Abellán, A., León, D., Ferreres, F., Guy, A., Oger, C., ... GilIzquierdo, A. (2018). Sorting out the phytoprostane and phytofuran profile in vegetable oils. Food Research International, 107, 619-628.

Durand, T., Bultel-Poncé, V., Guy, A., El Fangour, S., Rossi, J. C., \& Galano, J. M. (2011) Isoprostanes and phytoprostanes: Bioactive lipids. Biochimie, 93(1), 52-60.

El Fangour, S., Guy, A., Despres, V., Vidal, J.-P., Rossi, J.-C., \& Durand, T. (2004). Total synthesis of the eight diastereomers of the syn-anti-syn phytoprostanes F1 types I and II. The Journal of Organic Chemistry, 69(7), 2498-2503.

El Fangour, S., Guy, A., Vidal, J.-P., Rossi, J.-C., \& Durand, T. (2005). A flexible synthesis of the phytoprostanes B1 type I and II. The Journal of Organic Chemistry, 70(3), 989-997.

Hasanuzzaman, M., Hossain, M. A., da Silva, J. A. T., \& Fujita, M. (2012). Plant response and tolerance to abiotic oxidative stress: Antioxidant defense is a key factor. In B. Venkateswarlu, A. K. Shanker, C. Shanker, \& M. Maheswari (Eds.). Crop stress and its management: Perspectives and strategies (pp. 261-315). Dordrecht: Springer, Netherlands.

Heiss, E. H., Tran, T. V. A., Zimmermann, K., Schwaiger, S., Vouk, C., Mayerhofer, B., Dirsch, V. M. (2014). Identification of chromomoric acid C-I as an Nrf2 activator in Chromolaena odorata. Journal of Natural Products, 77(3), 503-508.

Jahn, U., Galano, J.-M., \& Durand, T. (2008). Beyond prostaglandins-chemistry and biology of cyclic oxygenated metabolites formed by free-radical pathways from polyunsaturated fatty acids. Angewandte Chemie International Edition, 47(32), 5894-5955.

Jahn, U., Galano, J.-M., \& Durand, T. (2010). A cautionary note on the correct structure assignment of phytoprostanes and the emergence of a new prostane ring system. Prostaglandins, Leukotrienes and Essential Fatty Acids, 82(2-3), 83-86.

Loeffler, C., Berger, S., Guy, A., Durand, T., Bringmann, G., Dreyer, M., ... Mueller, M. J. (2005). B(1)-phytoprostanes trigger plant defense and detoxification responses. Plant Physiology, 137(1), 328-340.

Marhuenda, J., Medina, S., Díaz-Castro, A., Martínez-Hernández, P., Arina, S., Zafrilla, P., Gil-Izquierdo, A. (2015). Dependency of phytoprostane fingerprints of must and wine on viticulture and enological processes. Journal of Agricultural and Food Chemistry, 63(41), 9022-9028.

Marseglia, A., Palla, G., \& Caligiani, A. (2014). Presence and variation of $\gamma$-aminobutyric acid and other free amino acids in cocoa beans from different geographical origins. Food Research International, 63, 360-366.

Marseglia, A., Sforza, S., Faccini, A., Bencivenni, M., Palla, G., \& Caligiani, A. (2014). Extraction, identification and semi-quantification of oligopeptides in cocoa beans. Food Research International, 63, 382-389.

Medina, S., Collado-González, J., Ferreres, F., Londoño-Londoño, J., Jiménez-Cartagena, C., Guy, A., ... Gil-Izquierdo, A. (2017). Quantification of phytoprostanes - bioactive oxylipins - and phenolic compounds of Passiflora edulis Sims shell using UHPLCQqQ-MS/MS and LC-IT-DAD-MS/MS. Food Chemistry, 229, 1-8.

Minghetti, L., Salvi, R., Lavinia Salvatori, M., Antonietta Ajmone-Cat, M., De Nuccio, C., Visentin, S., ... Durand, T. (2014). Nonenzymatic oxygenated metabolites of $\alpha$-linolenic acid B1- and L1-phytoprostanes protect immature neurons from oxidant injury and promote differentiation of oligodendrocyte progenitors through PPAR- $\gamma$ activation. Free Radical Biology and Medicine, 73(Supplement C), 41-50.

Morrow, J. D., Hill, K. E., Burk, R. F., Nammour, T. M., Badr, K. F., \& Roberts, L. J. (1990). A series of prostaglandin F2-like compounds are produced in vivo in humans by a non-cyclooxygenase, free radical-catalyzed mechanism. Proceedings of the National Academy of Sciences of the United States of America, 87(23), 9383-9387.

Nakabayashi, R., \& Saito, K. (2015). Integrated metabolomics for abiotic stress responses in plants. Current Opinion in Plant Biology, 24(Supplement C), 10-16.

Patras, M. A., Milev, B. P., Vrancken, G., \& Kuhnert, N. (2014). Identification of novel cocoa flavonoids from raw fermented cocoa beans by HPLC-MSn. Food Research International, 63, 353-359.

Pinot, E., Guy, A., Fournial, A., Balas, L., Rossi, J.-C., \& Durand, T. (2008). Total synthesis of the four enantiomerically pure diasteroisomers of the phytoprostanes E1Type II and of the 15-E2t-Isoprostanes. The Journal of Organic Chemistry, 73(8), 3063-3069.

Shah, Z. A., Li, R.-C., Ahmad, A. S., Kensler, T. W., Yamamoto, M., Biswal, S., \& Doré, S. 
(2010). The flavanol (-)-epicatechin prevents stroke damage through the Nrf2/HO1 pathway. Journal of Cerebral Blood Flow \& Metabolism, 30(12), 1951-1961.

Taber, D. F., Morrow, J. D., \& Jackson Roberts, L. (1997). A nomenclature system for the isoprostanes. Prostaglandins, 53(2), 63-67.

Torres-Moreno, M., Tarrega, A., Costell, E., \& Blanch, C. (2012). Dark chocolate acceptability: Influence of cocoa origin and processing conditions. Journal of the Science of Food and Agriculture, 92(2), 404-411.

Trigueros, L., \& Sendra, E. (2015). Fatty acid and conjugated linoleic acid (CLA) content in fermented milks as assessed by direct methylation. LWT - Food Science and Technology, 60(1), 315-319.
Waltenberger, B., Mocan, A., Šmejkal, K., Heiss, E. H., \& Atanasov, A. G. (2016). Natural products to counteract the epidemic of cardiovascular and metabolic disorders. Molecules (Basel, Switzerland), 21(6).

Yonny, M. E., Rodríguez Torresi, A., Cuyamendous, C., Réversat, G., Oger, C., Galano, J.M., ... Nazareno, M. A. (2016). Thermal stress in melon plants: Phytoprostanes and phytofurans as oxidative stress biomarkers and the effect of antioxidant supplementation. Journal of Agricultural and Food Chemistry, 64(44), 8296-8304.

Zhu, Y., Taylor, C., Sommer, K., Wilkinson, K., \& Wirthensohn, M. (2015). Influence of deficit irrigation strategies on fatty acid and tocopherol concentration of almond (Prunus dulcis). Food Chemistry, 173, 821-826. 